\title{
PARAMETRIZAÇÃO DA EMISSÃO TERMORADIATIVA APLICADA À ANÁLISE DO CONFORTO URBANO
}

\author{
Antonio Jaschke Machado* \\ $\&$ \\ Tarik Rezende de Azevedo**
}

\section{RESUMO:}

O experimento teve lugar em um percurso no interior do Campus CUASO (Cidade Universitária Armando Salles de Oliveira) da Universidade de São Paulo, no início da tarde do equinócio da Primavera de 2003, sob uma situação de céu claro típica do fim da estação sêca. A análise detalhada das observações do fluxo radiativo de onda longa termal (04 a 50 ?m) em todo o percurso apresenta padrões similares ao setor analisado em Machado e Azevedo (2005), conforme a cobertura do solo. Um índice de conforto externo ASV (NIKOLOPOULOU et al., 2002) modificado, que inclui alguns dos efeitos do fluxo de radiação de onda longa que podem ser sentidos por um pedestre, é sugerido. O novo índice parece representar de forma mais realista a sensação térmica em uma área heterogeneamente urbanizada. É aplicada uma parametrização (PRATA, 1996) do fluxo radiativo de onda longa recebido da atmosfera, sob uma situação de céu claro. O resultado é influenciado pelo padrão de ocupação do solo dominante no local onde os parâmetros meteorológicos são coletados, mas pode constituir-se em uma ferramenta interessante para implementação em índices de conforto ambiental.

\section{PALAVRAS-CHAVE:}

Conforto Urbano, Observações Móveis, Sensoriamento Remoto, Radiação Térmica, Parametrização.

\section{ABSTRACT:}

The experiment was performed in São Paulo, Brazil (UTM coordinates, lat $7.3910^{6}$ S, lon 3.24 $10^{6} \mathrm{~W}$, fuse $23^{\circ}$, SAD69), with a mobile transect inner the Campus of the University of São Paulo. It occurred at the beginning of the afternoon on the spring equinotium, under clear sky conditions typical of the end dry season in the region. The detailed analysis of the incoming long wave (thermal spectral range from 04 to 50 ? m) radiative flux observations at the transect presents distinct patterns related to the soil coverage. A modified comfort index, based on ASV (NIKOLOPOULOU et al., 2002), is suggested, including some long wave flux effects that can be sensed by a pedestrian. The new index represents in a more realistic way the thermal sensation in a heterogeneous urban area. Finally, it is applied the Prata (1996) parameterization of the long wave radiative flux received from the atmosphere. The result concerns with the observations in magnitude. Despite of the procedure to be influenced by the soil coverage patterns where the meteorological parameters are observed, it can be useful in the implementation of new environmental comfort indexes.

\section{KEY WORDS:}

Urban Comfort, Mobile Transects, Remote Sensing, Thermal Radiation, Parameterization.

*Pós-graduando em Geografia Física pelo Departamento de Geografia da FFLCH da Universidade de São Paulo. E-mail:jaschke.machado@usp.br ** Professor Doutor do Departamento de Geografia da FFLCH da Universidade de São Paulo. E-mail: xtarikx@usp.br 


\section{I - Introdução}

A radiação eletromagnética, da faixa do infravermelho termal (comprimento de onda aproximadamente entre 4,0 e 50,0 ? m) emitida tanto pela atmosfera como pelas diversas superfícies, é um importante termo do balanço de energia em áreas urbanas e pode constituirse em um bom indicador do grau de urbanização experimentado por uma determinada região. Isto decorre do fato de a atmosfera, bem como as diversas superfícies urbanas, serem compostas por uma grande variedade de constituintes e materiais, que acarretam uma maior variabilidade espacial da temperatura, possivelmente melhor avaliada se considerado o grau de emissão térmica dos diferentes elementos da paisagem. Aliado a esta perspectiva, há o fato de não haver ainda na RMSP (Região Metropolitana de São Paulo) uma rede radiométrica que possibilite a análise adequada de tal elemento, sobretudo devido aos elevados custos dos equipamentos necessários a tais mensurações. Surge, assim, a necessidade de desenvolvimento de novas técnicas e procedimentos metodológicos que viabilizem estas análises.

A atmosfera da cidade de São Paulo (situada a $23^{\circ} 33^{\prime} \mathrm{S}$ e $46^{\circ} 43^{\prime} \mathrm{O}$, aproximadamente a $770 \mathrm{~m}$ acima do nível do mar), assim como a atmosfera de outros grandes centros urbanos, caracteriza-se, fundamentalmente, por um enorme acúmulo de constituintes variáveis, além dos gases permanentes, na sua porção inferior próxima à superfície, onde se desenvolve a camada limite. Essa particularidade da camada limite atmosférica urbana implica em uma caracterização específica do clima para o ambiente urbano. A camada limite urbana é uma porção da atmosfera situada acima de uma área urbana, e cujas características climáticas são modificadas pela presença de uma cidade na superfície (OKE, 1978). As unidades climáticas urbanas, da cidade de São Paulo, segundo Tarifa e Armani (2001) são: unidade climática urbana central, unidade climática urbana da periferia, unidade climática do urbano fragmentado e unidade climática não-urbana.
Sob o ponto de vista da radiação solar, de onda curta, Oliveira et al. (2002 a) apresentam uma estimativa local da radiação solar global, cerca de $16 \%$ inferior a uma outra estimativa, de escala regional, obtida através de sensoriamento remoto. Essa variação, na quantidade de energia solar que atinge a superfície, em diferentes escalas, pode ser fruto da própria natureza urbana da atmosfera local que se manifesta através das observações pontuais do fenômeno. Com relação à radiação térmica de ondas longas o mesmo também pode ser verificado. Voogt e Oke (1997) estimam a temperatura radiativa da superfície em áreas urbanas através de observações no solo e aéreas, com pirgeômetros, considerando a área total da superfície que está emitindo radiação térmica. Notam, por estas observações, que as estimativas que consideram a superfície completa geralmente diferem de estimativas por sensores remotos (como satélites, por exemplo), por levarem em consideração medidas em diferentes direções, que não apenas a direção do nadir ${ }^{1}$. Aliás, a determinação da temperatura radiativa das superfícies, que estão emitindo, pode ser útil também na obtenção da difusão de calor sensível, da emissividade e da admitância térmica da superfície observada.

\section{II - Caracterização do Espaço Urbano}

$\mathrm{O}$ ambiente natural caracteriza-se por um estado estacionário, onde há equilíbrio entre a quantidade de energia fornecida e a paisagem resultante. Com a inserção do fator humano, surge um novo agente geomorfológico que rompe com este estado (NIR, 1983). Este desequilíbrio gerado pelo homem resulta na aceleração dos processos erosivos e na criação do ambiente urbano, sobrejacente à superfície natural. Os processos geomorfológicos antrópicos acabam por interferir na evolução do meio físico de maneira dramática para as populações urbanas. As aglomerações urbanas acabaram se transformando em enormes organismos que drenam o mundo para seu sustento (ROGERS e GUMUCHDJIAN, 2001), 
sendo que a dramaticidade brutal do processo poderia ser atenuada caso o tradicional modelo de metabolismo linear (fontes de energia orgânicas e nucleares, associadas à ausência de reciclagem de lixo) das cidades fosse substituído por um modelo de metabolismo circular (fontes de energia renováveis e reciclagem de lixo e resíduos).

A RMSP, um dos importantes aglomerados urbanos da América Latina, fica localizada no domínio morfoclimático e fitogeográfico denominado Mares de Morros. Este domínio é caracterizado originalmente por regiões serranas, tropicais úmidas e florestadas ( $A B$ 'SABER, 1967). Abrange uma área de cerca de $3.000 \mathrm{~km}^{2}$ e, segundo a classificação escalar apresentada por Fairbridge (1968), apresenta uma área de análise correspondente a magnitudes entre 4ạ e 5ạ ordem, nas quais destacam-se, como base de estudos geomorfológicos, as unidades estruturais de caráter regional restrito, a individualidade tectônica e o relevo simples.

Segundo Kretzschmar (1994), na RMSP $95 \%$ da eletricidade é gerada por usinas hidroelétricas, e as principais fontes de emissão de gases e partículas, para a atmosfera, de origem antrópica, são devidas às indústrias e ao tráfego de veículos. Eventos de poluição do ar, tais como altas concentrações de material particulado, podem causar reduções de 10 a 12 $\%$ dos valores horários e diários da radiação solar global na superfície (OLIVEIRA et al., 2002a).

O menor aquecimento da superfície urbana, devido à redução da incidência de radiação solar, está, no entanto associado a um outro efeito compensatório. Oke (1981) verificou um atraso no resfriamento, presumivelmente devido à diminuição da radiação líquida de onda longa (emissão térmica) na superfície do canyon, causada pela obstrução horizontal. Conforme a proporção A/L (altura/largura) do canyon aumenta, uma grande parte do céu frio (céu claro) é substituída por edificações, com paredes aquecidas em relação ao ar. Isto representa um importante efeito da geometria urbana no ambiente.

A análise do comportamento térmico e energético em áreas urbanas depende dos elementos superficiais que estão sendo investigados, conforme o tipo de experimento idealizado. Voogt e Oke (1997) definem seis categorias de superfície: completa (todas as superfícies são avaliadas), nível do solo (solo, ruas, calçamentos, vegetação e pisos), nível das coberturas (topos das edificações), visão "olho de pássaro" (os topos das edificações, ruas e topo da vegetação são avaliados), nível do pedestre (superfície aérea, distante cerca de 1,5 m acima do solo), deslocamento do plano zero (paralela ao nível do solo).

Grimmond e Oke (1995) expressam os fluxos de energia através do balanço em um volume, adjacente à superfície, tendo como resíduo a variação da quantidade de calor arm azenada neste volme $\mathrm{PQ}_{\mathrm{s}}$ ):

$$
? \mathrm{Q}_{\mathrm{S}}=\mathrm{K}^{*}+\mathrm{L}^{*}-\mathrm{Q}_{\mathrm{H}}-\mathrm{Q}_{\mathrm{E}}+\mathrm{Q}_{\mathrm{F}}-? \mathrm{Q}_{\mathrm{A}}
$$

$Q_{H}$ e $Q_{E}$ são o calor sensível e latente turbulentos, $K^{*}$ e $L^{*}$ são o saldo de radiação solar e térmica, ? $Q_{A}$ é a variação do calor advectado e $Q_{F}$ representa o calor liberado por fontes antropogênicas. Em áreas urbanas, devido à grande heterogeneidade das superfícies, os termos do balanço (B) podem ser discretizados através de uma área relativa ( $\mathrm{Hu}$ et al., 1999):

$$
\mathrm{B}^{\mathrm{D}}=\stackrel{?}{\mathrm{i} ? 1}^{\mathrm{N}} \quad \mathbf{a}_{\mathbf{i}} \mathbf{B}_{\mathbf{i}}
$$

O índice $i$ representa a tipologia de $N$ coberturas distintas do solo, em uma área $a_{i}$ do domínio $(D)$.

Em relação ao transporte de calor por advecção do fluxo médio que atravessa os canyons urbanos, Nunez e Oke (1977) avaliam o impacto dos fluxos de ar, paralelos às paredes do canyon, ou então cruzando o canyon. A primeira situação apresenta fluxos maiores de 
calor para intensidades maiores do vento (fluxo de energia de $50 \mathrm{Wm}^{-2}$ para ventos de $1 \mathrm{~ms}^{-1}$, e $170 \mathrm{Wm}^{-2}$ para ventos de $2 \mathrm{~ms}^{-1}$ ). No entanto, a segunda condição, com o vento cruzando o canyon, e induzindo um vórtice vertical no interior deste, foi difícil de ser avaliada quantitativamente. Devido talvez à mistura das propriedades do ar, gerada pelo vórtice, e a não suficiente resolução espacial da distribuição dos instrumentos.

Com relação à ventilação, o ambiente interior aos canyons tende a apresentar atenuação das circulações atmosféricas, tanto para brisas intra-urbanas que dependem de um ambiente termodinamicamente estável (THORSSON e ELIASSON, 2003 parametrizam a estabilidade atmosférica através do número adimensional de Richardson), como também para os fluxos de escala superior acima das coberturas. Para uma proporção A/L próxima a 1, Nakamura e Oke (1988) observam uma redução da ordem de $2 / 3$ com relação ao fluxo de ar acima do canyon. Na escala de um canyon, as circulações atmosféricas geradas em seu interior, a partir de um fluxo acima das coberturas, podem estar em oposição devido à ocorrência de vórtices que tendem a ser mais bem definidos tanto quanto o eixo do fluxo externo for ortogonal ao canyon.

Machado e Silva Dias (1997) analisam as circulações de ar na RMSP, porém em uma escala maior, a escala regional. Padrões distintos de verão, capazes de originar nevoeiros (MACHADO, 1993), especialmente nos fundos de vales, são analisados em uma resolução espacial de $4 \mathrm{~km}$. Um modelo numérico é aplicado em associação a observações realizadas em campo.

A caracterização do espaço urbano é complementada por uma análise, inicialmente qualitativa, do conforto ambiental. Foram selecionados dois locais, na RMSP, para realização desta análise.

O local considerado desconfortável está localizado na Av. Mercúrio (Fig.la e Fig.1b). Trata-se de uma área localizada no centro da cidade de São Paulo, entre a rua da Cantareira e a Av. do Estado, sobre uma região também conhecida como Várzea do Carmo. As imagens obtidas (Figs. la e 1b) correspondem às 11.00 h do dia 14 de Agosto de 2005 (Sábado). O local considerado confortável localiza-se no Parque da Água Branca, Zona Oeste da cidade de São Paulo. Fica sobre a porção inferior da vertente sul da Várzea da Barra Funda, ao lado do bairro de Perdizes, onde há atualmente intenso processo de verticalização. As imagens (Figs. 1c e $1 \mathrm{~d}$ ) correspondem às $11.00 \mathrm{~h}$ do dia $15 \mathrm{de}$ Agosto de 2005 (Domingo).

Analisando-se subjetivamente as localidades escolhidas e desconsiderando-se os aspectos de caráter psico-adaptativos, podese estabelecer algumas relações de ordem física. A localidade desconfortável (mínimo conforto) caracteriza-se por intensa ocupação do solo, prevalecendo a quase total impermeabilização. A atmosfera é poluída por gases e material particulado emitido dos veículos, e a sensação de ruído é elevada.

Com relação ao conforto termodinâmico, destacam-se dois setores. O setor intensamente verticalizado, onde prevalecem canyons tipicamente urbanos, com extensas áreas sombreadas (mesmo ângulo zenital solar pequeno) e propícios à canalização dos ventos, acarretando uma predominante sensação de frio. Por outro lado a área comercial, com edificações baixas ( 02 a 03 pavimentos). O fator de visão do céu é mais amplo, propiciando maior incidência de raios solares (inclusive com ângulo zenital solar elevado). No entanto, o intenso aquecimento solar, favorecido pela elevada admitância térmica dos materiais que constituem as superfícies, e também pelo efeito estufa, acarreta uma constante sensação de calor.

A localidade confortável (máximo conforto) caracteriza-se por um predomínio do solo aparente, gramado ou não, e sombreado por copas de grandes árvores. Estas árvores atenuam a incidência de radiação solar e ao mesmo tempo contribuem com uma proporção maior para a taxa de emissão térmica, 
funcionando simultaneamente como atenuador e contribuinte ao aquecimento, de tal forma que haja uma compensação por perda ou ganho de calor radiativo. Além disso funcionam como anteparos para ruídos excessivos e ventos mais fortes, resguardando as áreas internas de sua ação; também podendo funcionar como "filtros" de material particulado e gases poluentes das redondezas, elevando a qualidade do ar no interior do parque.

Em relação ao aspecto térmico de um parque arborizado deve-se destacar o efeito "termostato" característico da vegetação, que pode conservar a temperatura das folhagens quase constante, em situação de aquecimento do ar superior a $30^{\circ} \mathrm{C}$, aproximadamente.

Os espelhos d'água (não poluídos) são importantes reguladores de uma sensação térmica moderada, em oposição a situações extremas. São justamente as áreas menos sombreadas, implicando em maiores taxas de evaporação. O calor latente transferido para a atmosfera também contribui para que as áreas sombreadas do parque não estejam tão frias. Ao mesmo tempo em que há um favorecimento ao aquecimento mais lento da superfície.

As características termodinâmicas no interior de um canyon urbano podem apresentar conseqüências diretas ao estado de conforto dos pedestres. Destaca-se a importância da orientação do canyon em relação aos ventos predominantes na região e à incidência dos raios solares, além da estabilidade do ar que pode contribuir com a dissipação de poluentes. Uma situação de instabilidade pode facilitar a dispersão de poluentes.

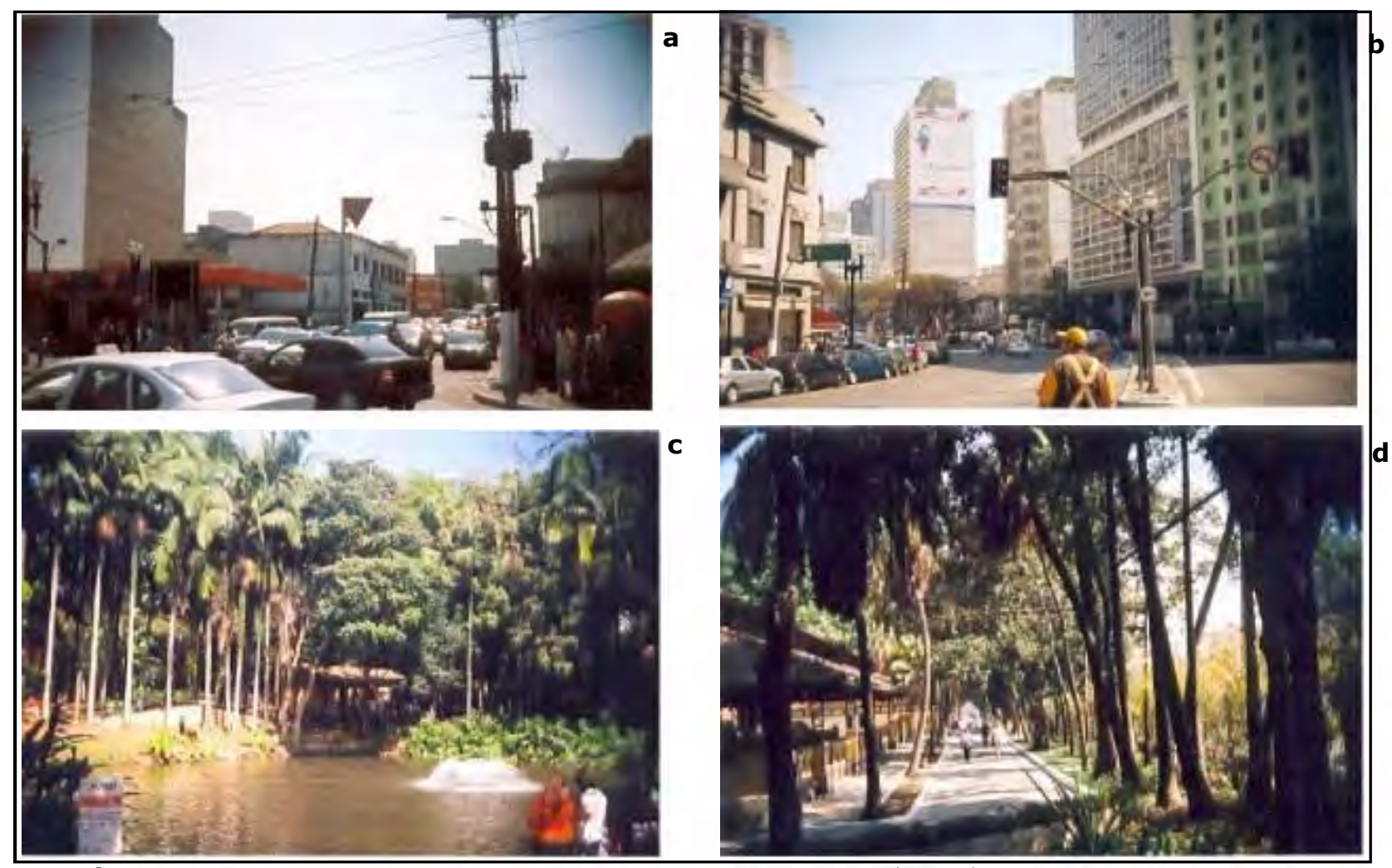

Figura 1 - Paisagens características de um setor comercial (a e b) e de um parque urbano ( c e d), considerado ambientalmente desconfortável e confortável, respectivamente. 


\section{III - Investigação Remota do Clima sobre a Superfície Urbana}

Voogt e Oke (2003) apresentam uma revisão sobre como evoluíram, durante os últimos 20 anos, os métodos de investigação dos climas urbanos através da utilização de sensores remotos termais, destacando-se a utilização de dados provenientes de satélites, já na segunda metade da década de 80 , com o propósito de investigação de ilhas urbanas de calor. Roth et al. (1989) levantam quatro questões fundamentais sobre o significado das informações obtidas remotamente por satélite, tendo em vista principalmente a complexidade da geometria das formas urbanas e o posicionamento do sensor em relação a esta superfície:

a. Quais são as características da superfície urbana vistas pelos sensores térmicos remotos?

b. Qual é a relação entre a temperatura radiométrica superficial observada remotamente e a temperatura verdadeira da interface urbana - atmosférica?

c. Como a ilha superficial urbana de calor pode estar relacionada à ilha atmosférica de calor?

d. Como o sensoriamento térmico das superfícies urbanas pode contribuir para 0 modelamento climático?

Ross e Oke (1988) analisam outra ferramenta emergente naquela mesma ocasião, os modelos numéricos (baseados no balanço de energia), cuja demasiada simplificação de soluções deve-se, basicamente, a três fatores limitadores: inicialização inadeqüada de alguns parâmetros, tais como: albedo superficial, comprimento de rugosidade e propriedades térmicas sub-superficiais; grande dificuldade em definir-se a superfície em uma área urbana; dificuldade em prognosticar-se os fluxos superficiais de calor em situações em que a evaporação não pode ser desprezada. Ainda hoje, o ponto mais fraco dos modelos numéricos de investigação do clima urbano continua sendo a solução do processo de evapotranspiração, que é o termo mais influente para a correta compreensão do particionamento da energia em uma superfície urbana. Apesar de prognosticarem razoavelmente bem o saldo radiativo, deixam a desejar em relação aos demais fluxos de calor devido à falta de uma representação apropriada da umidade superficial. Além disso, a variabilidade da temperatura do ar adjacente à superfície é um importante fator para um prognóstico satisfatório da temperatura superficial.

Com o objetivo principal de esclarecer as questões sobre os métodos de investigação do clima urbano através de sensores remotos, Voogt e Oke (1997, 1998 a, 1998 b), fazendo uso de diferentes métodos, realizam uma série de experimentos de campo sob diversos tipos de ocupação de solo, trazendo à tona a visão mais realística e completa possível sobre o que é a geometria urbana (admitidas algumas simplificações) e quais as faces desta superfície que são efetivamente enxergadas pelo sensor remoto. Neste contexto, lançam mão de uma série de radiômetros e equipamentos com sensor infravermelho, que, acoplados a aeronaves ou mesmo a automóveis sobre as vias da área urbana, fornecem um panorama do grau de precisão da temperatura superficial (vias, paredes e coberturas) obtida via satélite para a tipologia de superfícies definida a seguir.

Define-se a área completa $\left(A_{C}\right)$ de uma superfície urbana como a soma da área exposta do solo $\left(A_{O}\right)$, da área das edificações $\left(A_{e d}\right)$ e da área da vegetação $\left(A_{V}\right)$ :

$$
A_{C}=A_{O}+A_{e d}+A_{V}
$$

Considera-se área do solo como sendo a área plana total $\left(A_{p}\right)$, subtraídas as parcelas correspondentes às coberturas dos edifícios (Aped) e à copa das árvores ( $\left.A_{\text {copa }}\right)$ :

$$
A_{o}=A_{p}-\left(A_{\text {ped }}+A_{\text {copa }}\right)
$$


(4).

A área dos edifícios possui outra componente além de sua área plana (cobertura), que trata da área lateral (Aled) correspondente às paredes, tornando-se:

$$
A_{\text {ed }}=A_{\text {ped }}+A_{\text {led }}
$$

A área das coberturas é calculada para os $\mathrm{N}$ padrões de fachadas de edifícios observados ( $x$ a largura e y a profundidade), aplicando-se o teorema de Stokes:

$$
A_{\text {ped }}=1 / 2 ?_{i ? 1}^{N ? 1}\left(x_{i} y_{i+1}-y_{i} x_{i+1}\right)+x_{N} y_{1}-
$$
$\mathrm{x}_{1} \mathrm{y}_{\mathrm{N}}(6)$.

Para o cálculo da área lateral substituise $x$ por $z$ e y por $z$, sucessivamente, onde $z$ representa a altura da edificação.

A área da vegetação corresponde a uma fração da área da copa das árvores:

$$
A_{V}=\left(F_{\text {gap }}\right)^{-1} A_{\text {copa }}
$$

definida por um fator ( $F_{\text {gap }}$ ) que equivale ao inverso da densidade foliar. Esta densidade possui variabilidade sazonal e é definida para cada espécie vegetal.

A partir do momento em que se conhece a fração (área) com que cada superfície distinta contribui para a superfície urbana completa, pode-se efetuar a correção do fluxo radiativo de onda longa observado ( $R$ ), relativamente ao fluxo real (L) com que a superfície emite, levando-se em conta a emissividade (?) desta superfície:

$$
\mathrm{L}=(1 / \text { ?) } \mathrm{R}
$$

Onde, $R$ é produto das diversas contribuições inerentes a um determinado alvo ( paredes - led, céu - a, piso - p), observado por um certo fator de visão (?), em uma situação com edifícios adjacentes (índices 1 e 2):

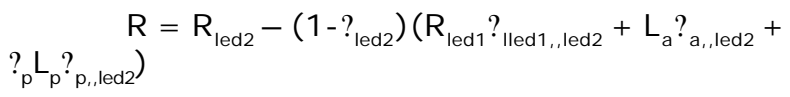

No entanto, vale ressaltar que todos os métodos remotos podem ser aferidos de maneira direta. Sobretudo acoplando-se termopares, no caso de investigação térmica, diretamente sobre a superfície, que é alvo do sensor remoto. Porém, devido a implicações logísticas para a realização de tais experimentos, são concebidas alternativas escalares (VOOGT e OKE, 1991; SPRONKENSMITH e OKE, 1999), que permitem o modelamento físico da estrutura térmica aproximada, da superfície de canyons e parques urbanos.

Baseados em sua própria experiência e nos inúmeros resultados alcançados por outros pesquisadores, sobretudo durante a década de 90, Voogt e Oke (2003) propõem a seguir possíveis respostas para as quatro questões levantadas por Roth et al. (1989).

Em escalas menores a descrição de áreas urbanas tem se desenvolvido devido à utilização de modelos SIG. Em escalas maiores, conjuntos de dados (cobertura detalhada do solo), obtidos a partir de observações de campo ou a partir de sensoriamento remoto têm contribuído para uma melhor compreensão da superfície urbana em relação aos balanços de energia. No entanto, estes dados não têm sido relacionados aos parâmetros estruturais que poderiam ser utilizados para melhor definir a superfície urbana em modelos de visão do sensor.

A estimativa de temperaturas superficiais, através de sensores remotos, está sujeita, basicamente, a dois efeitos, atmosférico e característica superficial, que tendem em geral a subestimar os valores reais.

Os efeitos atmosféricos devem-se sobretudo, à absorção e à emissão de L pelas diversas camadas de ar. Atualmente 
já existem soluções bem estabelecidas para este efeito, possíveis graças à inserção de perfis hidro-térmicos da atmosfera em modelos numéricos (LOWTRAN, MIDTRAN ou HIGHTRAN), que resolvem o balanço de $L$ através dessas camadas. Todavia, deve-se ressaltar a importância de um melhor conhecimento das distribuições espaciais da transmissividade atmosférica sobre as áreas urbanas, tendo em vista que variações na quantidade de radiação solar transmitida implicarão em distintas taxas de aquecimento da superfície, e, conseqüentemente, em uma distribuição espacial mais complexa da temperatura superficial.

Com relação à emissividade superficial a natureza tri-dimensional complexa da superfície urbana implica em dois aspectos complicadores. Primeiramente, o surgimento de complexos padrões microescalares, influenciados pelas diversas propriedades térmicas e orientações geográficas das faces que compõem a superfície urbana. E em segundo lugar, o fato de os sensores utilizarem fatores de visão muito estreitos em suas medições, acarretando uma visão enviesada da área observada. Este último aspecto implica em uma situação de anisotropia efetiva da radiação de onda longa emitida pela superfície (L?).

Ainda não foi possível encontrar uma relação direta simples entre ilha superficial de calor e ilha atmosférica de calor. O principal problema reside no fato de que as áreas fonte, sobretudo para os fluxos turbulentos de calor, são distintas em cada uma das situações analisadas (superfície e atmosfera). Todavia, deve-se notar que é possível a obtenção de correlações mais satisfatórias entre temperatura do ar e da superfície (análise em escalas menores) principalmente à noite, quando em geral há considerável enfraquecimento da advecção turbulenta de microescala. Pesos estatísticos têm sido considerados em relação às superfícies não vistas pelo sensor, reduzindo-se, assim, em alguns casos, a diferença estimada entre as temperaturas da superfície e do ar. Ou seja, com relação a estes aspectos, é primordial o desenvolvimento de estudos combinados visando-se a utilização tanto de modelos da atmosfera como também da superfície.

Para melhor conceituação do clima urbano, a partir de observações remotas, persiste a dificuldade em relação ao modelamento da superfície rugosa urbana. Os maiores progressos foram obtidos em modelagem de fluxos de calor sensível em relação a superfícies vegetadas. Devido à anisotropia inerente das superfícies urbanas, torna-se muito difícil determinar uma relação entre a temperatura radiativa (obtida através das propriedades radiativas) e a temperatura aerodinâmica (obtida através das propriedades termodinâmicas). Métodos que relacionam temperatura e índices de vegetação (NDVI) também têm sido aplicados para investigação de alterações superficiais sobre áreas urbanizadas, tal como o método denominado triangular, que combina, de uma só vez, os modelos de transferência atmosférica, de vegetação e de solo (SVAT).

As árvores são componentes importantes da camada urbana. Elas são responsáveis por importantes efeitos de troca de energia em todas as escalas da cidade, especialmente na pequena escala que compreende o canyon urbano (Fig. 2). No entanto, a compreensão destes efeitos e sua aplicação diminuem conforme a escala aumenta, desde o canyon viário, para o parque, para a ocupação do solo, até se atingir a cidade como um domínio total. 


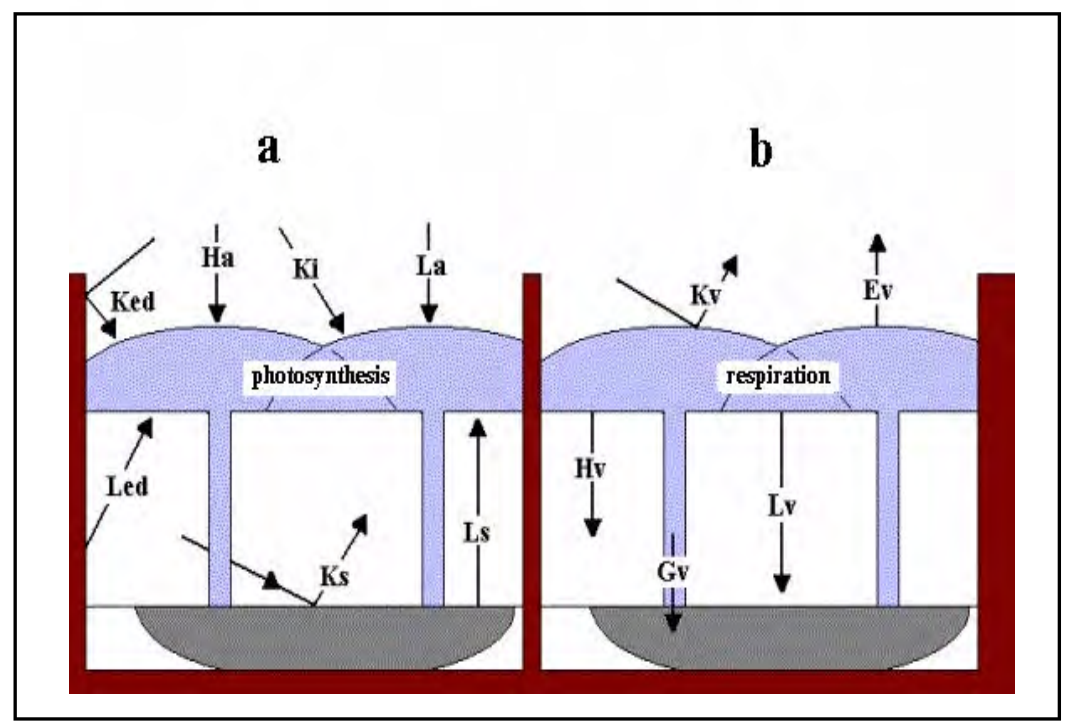

Figura 2 - Esquema vetorial simplificado do balanço diurno de energia ( $\mathbf{L}_{\mathrm{a}}$ - emissão atmosférica, $L_{v}$ - emissão da vegetação, $L_{e d}$ - emissão dos edifícios) em um canyon urbano arborizado, considerando-se uma situação com ganho (a) e outra com perda (b) de energia (adaptado de OKE, 1989).

\section{IV - Instrumentos e Métodos}

O desenvolvimento e implementação de equipamentos e instrumental para mensuração das condições climáticas e ambientais, como minirregistradores (AZEVEDO e TARIFA, 2002), é sempre interessante pois pode criar alternativas de mais baixo custo e de mais fácil aplicação, inclusive em aferições no meio urbano.

Para a determinação das condições de
conforto urbano tem-se utilizado parametrizações das variáveis ambientais, em função da opinião pessoal coletada a partir de uma amostra; como também modelos numéricos de conforto baseados na geometria do corpo humano (YANAGIHARA, 2005), cuja utilização é útil em situações onde a exposição ao calor, ou ao frio, não é homogênea.

Neste trabalho utilizou-se um pirgeômetro acoplado sobre um veículo (Fig.3) para obtenção da distribuição do fluxo radiativo de onda longa recebida (L?) através de um percurso urbano arborizado (Fig. 4). Utilizou-se um pirgeômetro Eppley, modelo PIR, e um veículo Ford, modelo KA. O conjunto de equipamentos utilizados inclui também um computador portátil, um datalogger Campbell modelo $21 \mathrm{X}$ e uma bateria de $12 \mathrm{~V}$. O arranjo experimental está ilustrado em Machado e Azevedo (2004).

A emissão real das superfícies é aproximada à emissão térmica aparente observada ( $L$ ? R). Considerando-se como relativamente pequena a distância entre o sensor e o alvo (apenas alguns metros), desprezou-se a correção atmosférica. Além disso, os valores elevados de emissividade, mencionados na literatura, para copas de árvores e vegetação em geral, assume-se um comportamento próximo a de um corpo negro para estes alvos. O procedimento de calibração do sensor utilizado é descrito em Oliveira et al. (2002 b).

O método baseia-se nos trabalhos de 
Voogt e Oke (1998 b; 1997) e Sakamoto (2001), consistindo na escolha de trajetórias no interior da CUASO (Cidade Universitária Armando Salles de Oliveira) - Campus da Universidade de São Paulo (zona Oeste da RMSP), analisadas quanto à tipologia de ocupação do solo.

Foi idealizado um percurso, composto de transectos, conforme Sakamoto (2001), através dos quais a densidade do fluxo de $L$ ? é observada. A hipótese investigada parte da premissa de que a influência sobre o conforto humano em áreas urbanas é de menor impacto devido à variação da temperatura do ar, mas de grande relevância ao se considerar o campo espacial de L?.

Dentre as dificuldades encontradas destaca-se o nivelamento do sensor ao plano horizontal devido tanto ao movimento da suspensão do veículo ao percorrer a trajetória como pela própria configuração altimétrica do terreno. No entanto, estas dificuldades parecem não influenciar drasticamente as medições de radiação térmica, assumindo-se a hipótese de as superfícies das copas das árvores (que, juntamente com a atmosfera, constituem os principais alvos na direção normal ao sensor $L_{a}$ e $L_{v}$ ) comportam-se como superfícies Lambertianas para os comprimentos de onda

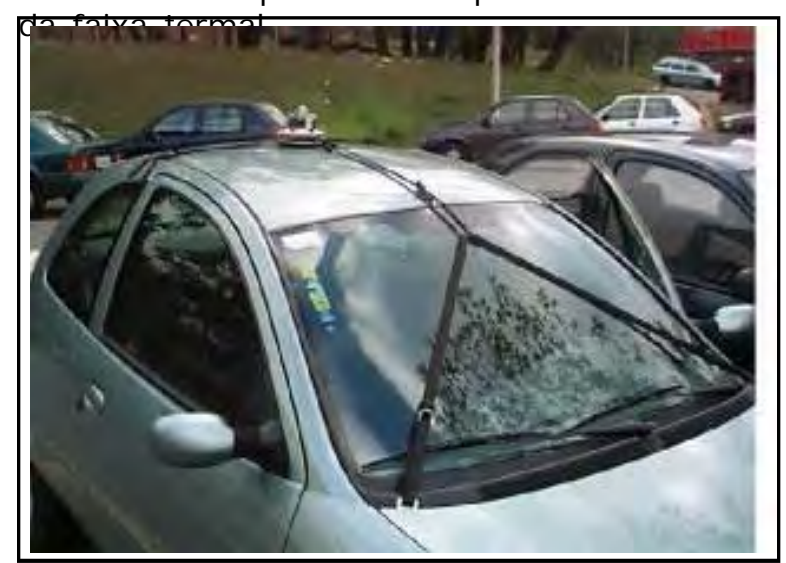

Figura 3 - Arranjo experimental com automóvel e pirgeômetro acoplado sobre sua cobertura.
Os dados foram coletados com uma freqüência amostragem de $10 \mathrm{~Hz}$, enquanto o armazenamento ocorreu a uma freqüência de $0,5 \mathrm{~Hz}$, obtendo-se assim um valor médio a cada 2 segundos sobre um conjunto de 20 valores amostrados. Este intervalo corresponde justamente à inércia instrumental do sensor. Optou-se por uma freqüência de amostragem 20 vezes superior, tentando-se investigar possíveis flutuações de alta freqüência causadas por campos eletromagnéticos gerados por torres de telecomunicação. Somente dessa forma o valor médio pode ser considerado confiável.

A velocidade de deslocamento do veículo oscilou em torno de $40 \mathrm{kmh}^{-1}$. Na literatura encontram-se velocidades máximas em torno de $60 \mathrm{kmh}^{-1}$ para veículos equipados para experimentos similares. Há indícios de que velocidades superiores a $70 \mathrm{kmh}^{-1}$ podem contribuir a um efeito oposto ao resfriamento, com o atrito do ar sobre os sensores acarretando aquecimento.

O experimento ocorreu no início do período vespertino de 23 de setembro de 2003 (equinócio da Primavera) sob condições de tempo estável, com céu praticamente claro, com ocorrência de cirrus esparsos em aproximadamente $1 / 4$ da abóboda celeste. As condições foram típicas do fim da estação seca na região.

Os dados foram geo-referenciados a partir da interpolação temporal das coordenadas geográficas em um conjunto de localizações amostradas. O geo referenciamento foi realizado com a utilização de um GPS (Geographic Position System) manual da GARMIN.

O cálculo final de $L$ ?, para a faixa espectral de comprimento de onda situada entre 04 e 50 ? m, leva em conta o procedimento sugerido pelo fabricante (Eppley Lab Inc.), sendo que não é aplicada a correção indicada por Fairall et alii (1998), que leva em consideração o aquecimento do corpo do aparelho e da cúpula 
do sensor pela incidência de radiação solar. Todavia, espera-se que esta correção seja mínima em experimentos como este, considerando-se o resfriamento induzido à cúpula e ao corpo do aparelho devido ao deslocamento de ar pelo movimento do veículo, bem como a curta exposição aos raios solares, já que o trajeto total foi percorrido em aproximadamente 4 minutos. Considerando-se as propriedades térmicas dos materiais que constituem o corpo do aparelho e da cúpula do sensor (cobre e silício) as suas dimensões, um comportamento radiativo similar a de um corpo negro e o fluxo de energia radiativa (onda curta) incidente sobre ele durante o período ( $\sim 4 \mathrm{~min}$ ) em que durou o percurso, obtém-se um aquecimento médio em torno de $1^{\circ} \mathrm{C}$ acima do equilíbrio térmico inicial com o ar, para uma situação extrema, com céu claro durante todo o percurso e não levando em conta o sombreamento eventual pela copa das árvores. Se forem consideradas ainda as propriedades físicas do ar seco (situação com pouca umidade), pode-se calcular o fluxo necessário para compensar o aquecimento do aparelho. Nas condições deste experimento estima-se um fluxo mínimo necessário de $2,7 \mathrm{~km} \mathrm{~h}^{-1}$.
A localização do percurso seguido foi orientada pela ocupação do solo, e foi escolhido o perímetro em torno da FFLCH (Faculdade de Filosofia, Letras e Ciências Humanas), com uma extensão total aproximada de $2,5 \mathrm{~km}$ e declividade variável e suave. Este trajeto escolhido está caracterizado na Figura 4, tanto em relação à cobertura do solo (Fig.4a) como em relação ao balanço da radiação recebida pela superfície (Figs. $4 b$ e $4 c): K$ ? + L?. A atmosfera e os elementos que compõem a ocupação do solo (edificações e vegetação) emitem uma parcela de radiação de onda curta $(K)$, além de $L$ que está sendo medido (Figs. 4b e 4c). Parte da radiação solar que incide na atmosfera $\left(K_{i}\right)$ é absorvida $\left(K_{a}\right)$, sendo que o restante pode ser transmitido na mesma direção $\left(K_{t}\right)$ ou então espalhado $\left(K_{e}\right)$ em outras direções, também contribuindo para o aquecimento das superfícies. Neste modelo sugerido, a quantidade $L$ ? total que atinge a superfície é composta por uma parcela emitida pela atmosfera $\left(L_{a}\right)$, uma segunda parcela emitida pelas edificações $\left(L_{e d}\right)$ e uma terceira emitida pela copa das árvores $\left(\mathrm{L}_{\text {copa }}\right)$. O terceiro termo é aproximado à emissão da vegetação, $L_{v} @ L_{c o p a}$ incluindo-se a emissão de troncos e galhos na mesma componente temática.

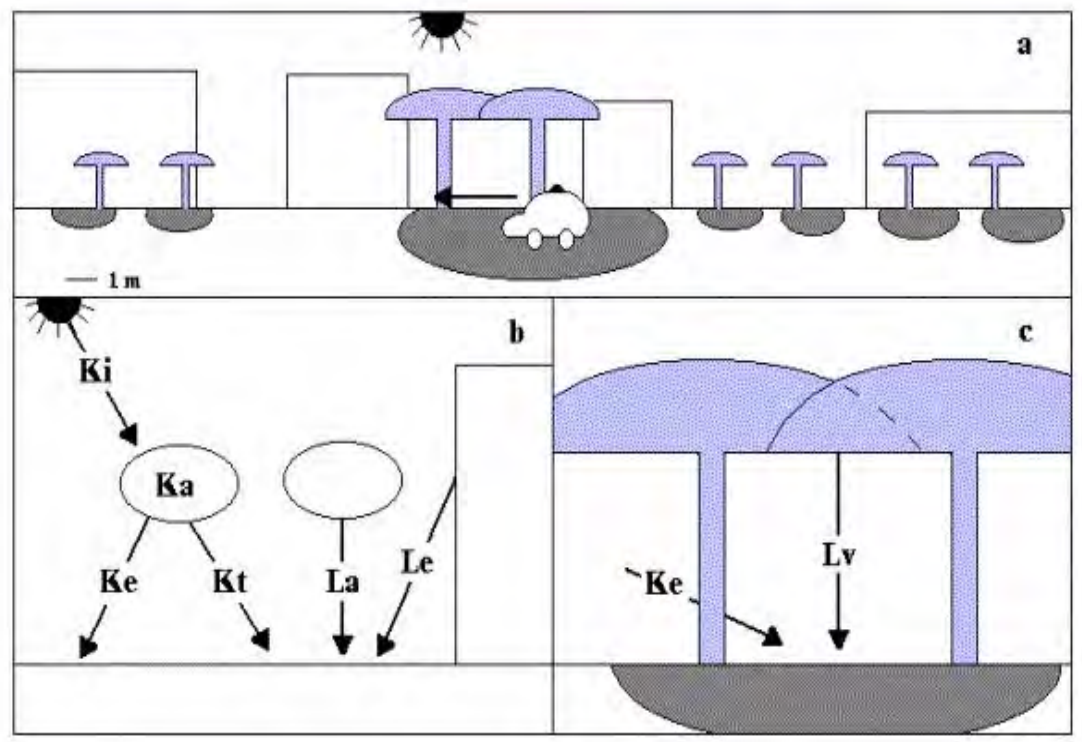

Figura 4 - Caracterização da cobertura do solo para o percorrido (a) e do balanço radiativo incidente na superfície, inicialmente em um trecho não vegetado (b) e posteriormente em um trecho arborizado (c). 


\section{V - Resultados}

O propósito dos experimentos realizados no perímetro (Fig. 5) em que se situa a Faculdade de Filosofia, Letras e Ciências Humanas (FFLCH) da Universidade de São Paulo (USP), no Campus da Cidade Universitária Armando Salles de Oliveira (CUASO), localizada no bairro do Butantã da cidade de São Paulo, é identificar padrões de emissão associados a elementos previamente conhecidos que compõem a ocupação do solo neste perímetro. Elementos como tipo de vegetação, cobertura do solo e intensidade do tráfego de veículos podem atuar interferindo na magnitude de $L$ ? observada. Verificam-se, em uma primeira análise, valores mínimos de emissão térmica da atmosfera (em torno de $320 \mathrm{Wm}^{-2}$ ) e picos máximos superiores a $400 \mathrm{~W} \mathrm{~m}^{-2}$.

O perímetro apresenta uma extensão total aproximada de $2,5 \mathrm{~km}$, com o maior setor retilíneo representado pela Avenida Prof. Luciano Gualberto $\left(A_{L G}\right)$, que apresenta um aclive bastante suave, implicando em uma variação topográfica em suas extremidades da ordem de $10 \mathrm{~m}$. A maior parte do percurso apresenta uma situação aproximadamente plana, com declividades estimadas da ordem de $10^{-2}$. Nos setores entre a Travessa $12\left(T_{12}\right)$ e a Rua do Lago $\left(R_{L}\right)$ ocorrem declividades um pouco superiores, da ordem de $5 \cdot 10^{-1}$. O aquecimento radiativo da superfície, por incidência da radiação solar, é ligeiramente reduzido nestes dois setores do percurso devido à declividade um pouco mais acentuada.

A caracterização da distribuição espacial do fluxo de L? no percurso (Fig. 5) fica bem definida na Figura $6 a$, onde é realizada uma média móvel (Fig. 6b), sempre sobre um conjunto de dez valores observados. Com isto, são eliminadas as flutuações de maior freqüência e obtém-se uma visão mais objetiva do panorama da emissão atmosférica através deste perímetro escolhido. Ou seja, em termos médios, a emissão atmosférica observada apresenta valores mínimos entre 320 e 360 W $\mathrm{m}^{-2}$ e valores máximos entre 360 e $400 \mathrm{~W} \mathrm{~m}^{-2}$.
Há uma amplitude de cerca de $60 \mathrm{Wm}^{-2}$ nas observações realizadas. O fluxo mínimo corresponde a um panorama padrão observado, onde há presença de prédios baixos ( 2 ou 3 andares) e árvores menores ( 1 a $2 \mathrm{~m}$ ) obstruindo apenas parcialmente a visão do céu (Figura 6a). No entanto, há um padrão com máximo bem definido que se repete por três vezes no transcorrer do percurso (Figura 6b).

Analisando-se as características de obstrução da visão do céu para os três setores do percurso, verifica-se a repetição de um mesmo padrão, com elevação da obstrução devida à presença de árvores maiores (de 3 a $4 \mathrm{~m}$ de altura, ou mais), com copas mais amplas e não podadas. De tal forma que as copas destas árvores, dominantes no campo de visão do sensor, estão emitindo uma quantidade suplementar de radiação térmica para a superfície nas três posições $\left(R_{L}, A_{L G}\right.$ e $\left.T_{12}\right)$ indicadas na Figura $6 \mathrm{~b}$. As diferenças encontradas $\left(60 \mathrm{Wm}^{-2}\right)$ entre os valores médios em uma área com céu desobstruído e outra arborizada são ligeiramente superiores à diferença encontrada $\left(\sim 40 \mathrm{Wm}^{-2}\right)$ por Iziomon et al. (2003) entre uma localidade montanhosa e outra sobre um fundo de vale.

Assim sendo, observa-se que o padrão de emissão térmica analisada em Machado e Azevedo (2005), correspondente ao setor $A_{L G}$ repete-se de forma semelhante e consistente para os outros dois setores apresentados neste trabalho $\left(R_{L}\right.$ e $\left.T_{12}\right)$. Considerando-se que as características geométricas da vegetação (altura e largura das copas das árvores) são semelhantes para os três setores investigados, são assumidos aqui os resultados daquela análise em relação ao fluxo radiativo recebido pela superfície. Ou seja, elevação de cerca de $18 \%$ do fluxo de radiação térmica observada nos trechos mais arborizados. Bem como uma estimativa de redução do total de energia radiativa (onda curta + onda longa) recebida $(\mathrm{K}$ ? +L?) próximo à superfície (desconsiderandose a altura do veículo) da ordem de $50 \%$ entre locais não arborizados e densamente arborizados, observando-se uma situação de 
céu claro, sem advecção, no fim da estação de inverno (seca, para um clima tropical) e no horário entre os máximos aquecimentos diurnos, consecutivos, da superfície e do ar.

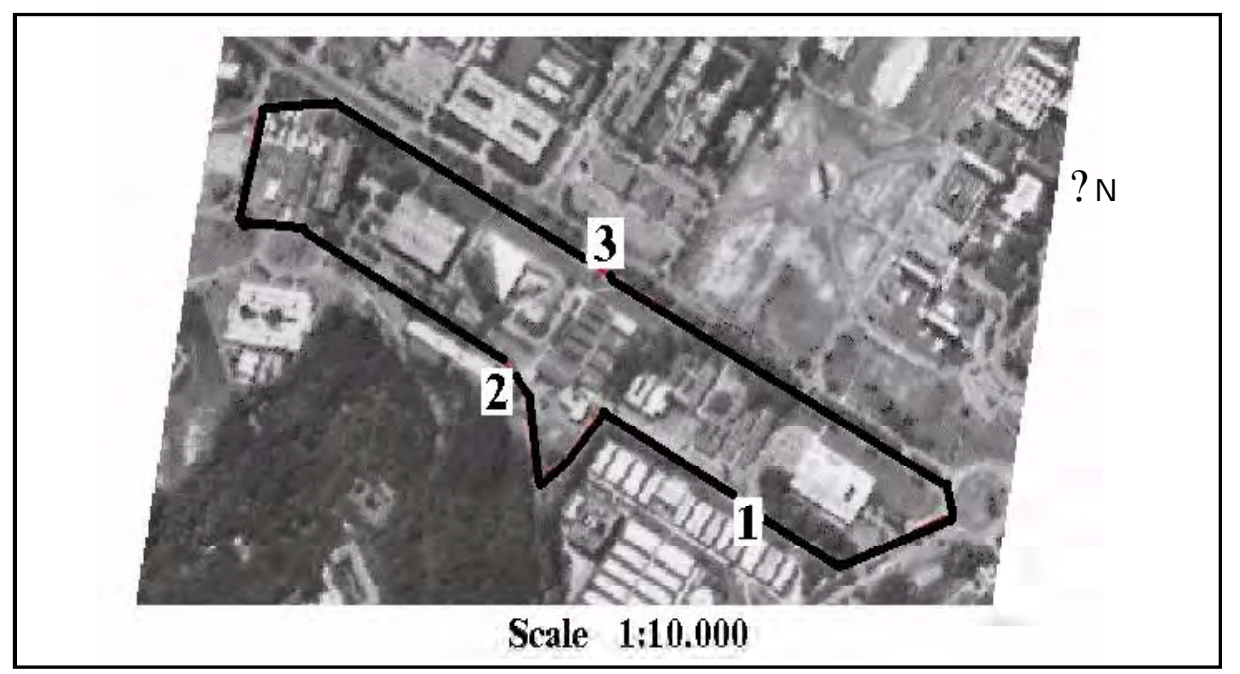

Figura 5 - Trajeto percorrido (sentido horário) pelo arranjo experimental da Figura 3 ao redor do polígono em que está localizada a FFLCH / USP, na CUASO, sendo indicadas as posições médias dos setores $\quad T_{12}(1), R_{L}(2)$ e $A_{L G}(3)$. O percurso teve início e encerrou-se na posição 1.

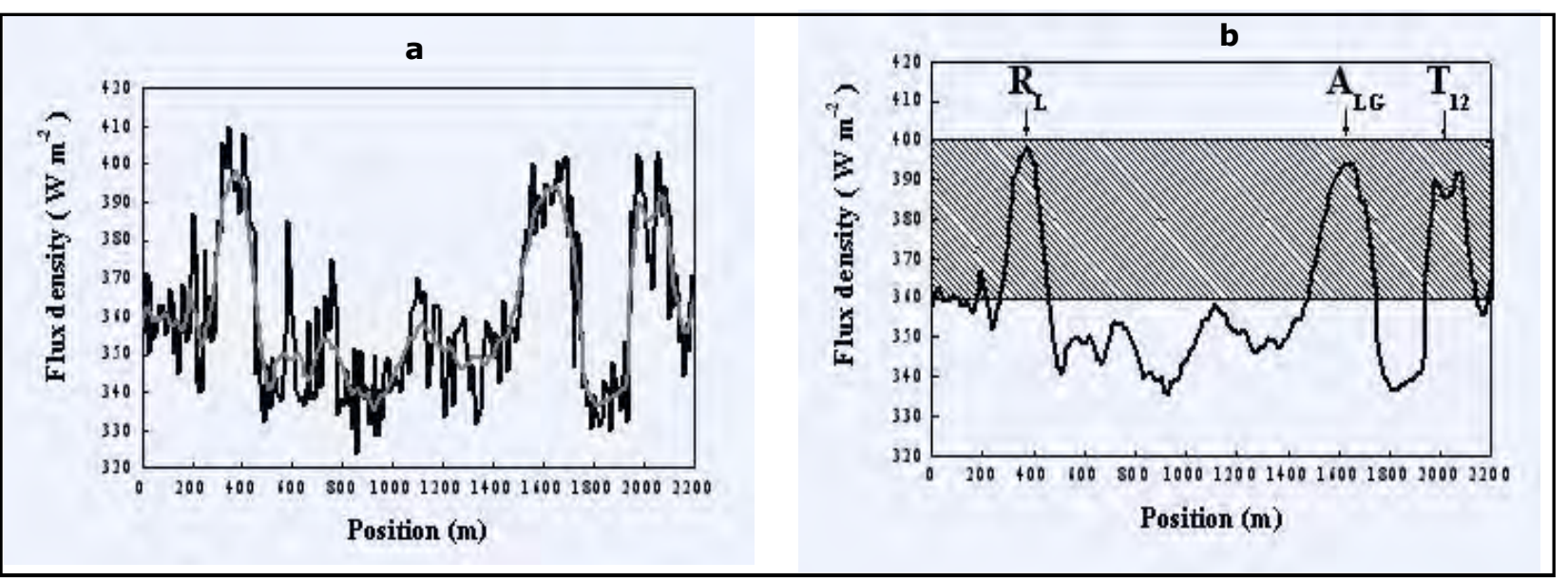

Figura 6 - Distribuição espacial da densidade de fluxo L? (a), observada com o arranjo experimental da Figura 3 através do trajeto apresentado na Figura 5, com a linha clara suavizada correspondendo à média móvel tomada a cada dez valores amostrados. A área hachureada, sobre a curva média (b), representa o intervalo radiométrico de L? que corresponde a maior obstrução do céu pelas árvores. Note-se que as posições 0 (início) e $2200 \mathrm{~m}$ (fim) do percurso são coincidentes e ambas correspondem à posição 1 (Fig.5). 


\section{VI - Índice de Conforto em um Percurso Urbano Arborizado}

Nikolopoulou et al. (2002) apresentam o índice de conforto térmico ASV (Actual Sensation Vote), que representa a opinião de sensação térmica presente de uma amostra de indivíduos.

O índice ASV foi modelado para uma série de cidades do continente europeu a partir de análise estatística correlacional com algumas variáveis ambientais: temperatura $(T)$ e umidade relativa do ar (UR), intensidade do vento (V) e fluxo radiativo de onda curta (K?) recebida. A partir desta análise, e combinando-se os resultados entre todas as cidades investigadas, obteve-se uma expressão que seria representativa para o continente:

\section{2,079 (10).}

$A S V=0,049 T+0,001 K ?-0,051 V+0,014 U R-$

Sendo que valores positivos de ASV estão relacionados a uma sensação térmica de calor, enquanto que valores negativos representam uma sensação térmica de frio.

Considera-se, para interpretação dos resultados, o valor $\mathrm{ASV}=0$ correspondente a uma sensação de pleno (máximo) conforto térmico. Para valores negativos ou positivos de ASV considera-se haver um estado de desconforto, com sensação de frio ou calor, respectivamente.

A análise propõe a implementação do fluxo L? recebido em um canyon urbano arborizado, como um elemento adicional a ser considerado no cálculo de ASV. A motivação para a busca desta estimativa repousa sobre as palavras de Givoni (1998):

"... em climas muito ensolarados, o sombreamento de paredes por árvores pode ser contra produtivo, pois também se reduz a perda de calor por emissão de onda longa. A interação entre sombreamento e efeitos de isolamento ainda não foi completamente estudada em investigações anteriores ..."

A situação estudada corresponde ao mesmo padrão de $L$ ? apresentado na Figura $6 b$ (setor oeste da RMSP, início da tarde, em torno das 13.00 horas local do dia 23 de setembro de 2003), sob um estado climático típico do final de inverno para a região. Com céu praticamente sem nuvens e situação de circulações atmosféricas calmas $(\mathrm{V}=0)$. A temperatura do ar e a umidade relativa ( $\sim 10 \mathrm{~m}$ acima da superfície) estavam sendo monitoradas a uma distância média de $100 \mathrm{~m}$ do percurso analisado (estação meteorológica do Laboratório de Climatologia e Biogeografia - FFLCH/USP), e, durante o período da realização do percurso, oscilaram em torno de $31,5^{\circ} \mathrm{C}$ e $27 \%$, respectivamente.

São consideradas duas situações: uma não sombreada, e outra sombreada pelas árvores do canyon; com os seguintes fluxos radiativos característicos: $\mathrm{L}$ ? $=330 \mathrm{Wm}^{-2}$ e $\mathrm{K}$ ? = $654 \mathrm{Wm}^{-2}$, além de $L$ ? $=390 \mathrm{Wm}^{-2}$ e $\mathrm{K}$ ? $=68,5$ $\mathrm{Wm}^{-2}$, simultaneamente. Os fluxos radiativos de onda curta recebida são sazonalmente representativos do local estudado (OLIVEIRA et al., 2002a).

As seguintes aproximações são realizadas. Utiliza-se a formulação de ASV obtida para as cidades européias (Eq. 10), considerando-se as características morfológicas de superfície semelhantes entre estas cidades e o local analisado. Concomitantemente, os fluxos radiativos ( $K$ ? e L?), aplicados ao cálculo de ASV, equivalem às taxas recebidas pelo canyon. Os fluxos radiativos refletidos $\left(K_{e d}\right)$ e emitidos $\left(L_{e d}\right)$ pelos elementos construídos do canyon não são considerados. Com relação a $\mathrm{K}$ esta aproximação é satisfatória, tendo em vista o calçamento do canyon (albedo muito baixo) e a proporção A/L (altura/largura) para este canyon (significativamente baixa), o que reduziria o impacto de $\mathrm{K}_{\text {ed }}$ refletido sobre um indivíduo posicionado sobre o piso do canyon. No entanto, na não consideração do $L_{e d}$ emitido pelo canyon deve residir a maior fonte de erro desta aproximação.

Inicialmente, considera-se apenas K?, conforme a formulação original. São obtidos os seguintes valores: $A S V=0,50$ no setor do 
trajeto em que predomina céu aberto e ASV = 0,09 no setor arborizado do trajeto percorrido.

A proposta de inclusão do fluxo L? na formulação de ASV deve então levar em conta a sua descrição climatológica para o local estudado. Considerando-se valores médios de L? para o local analisado (OLIVEIRA et al., 2002 b) defini-se um limiar mínimo, associado à sensação de frio, em torno de $300 \mathrm{Wm}^{-2}$ para madrugadas de inverno sob céu aberto. Por outro lado, define-se um limiar máximo, associado à sensação de calor, em torno de 400 Wm-2 para tardes de verão sob céu aberto. Desta forma, tem-se um valor em torno de 350 $\mathrm{Wm}^{-2}$ definido como paradigma de conforto, em termos de L?, para situações climáticas intermediárias. Interpolando-se estes extremos (300 e $400 \mathrm{Wm}^{-2}$ ) para uma faixa de conforto em torno do valor ideal de ASV (nulo), obtémse um coeficiente de 0,001 para L? semelhante ao utilizado para $\mathrm{K}$ ? ?

Portanto, tem-se um novo modelo proposto para o conforto térmico, considerandose a intensidade total de todas as componentes temáticas de $L$ que são observadas pelo sensor:

$$
\mathrm{ASV}^{*}=\mathrm{ASV}+0,001 \mathrm{~L} \text { ? }
$$

Conseqüentemente, chega-se a novas estimativas do conforto térmico para a situação estudada aqui, sendo ASV $=0,83$ no setor do trajeto em que predomina céu aberto e $A S V=0,30$ no setor arborizado do trajeto percorrido.

Nota-se, desta maneira, que a sensação de calor é maior tanto para o setor sob céu aberto quanto para o setor arborizado. No entanto, sob a área arborizada, a sensação de calor ainda permanece dentro do próximo ao ideal de conforto, sendo que de uma ligeira sensação de frio atinge-se uma sensação consistente de calor.

Este método parece apresentar uma boa perspectiva de aplicação quando desenvolvido em associação com as tabelas temporais de Olgyay, pelas quais o novo índice ASV* poderia ser utilizado em substituição às informações da carta bio-climática. Sobretudo em situações de sub-aquecimento, quando se deseja determinar a quantidade de $L$ necessária para recuperação da sensação de conforto (GIVONI, 1998).

\section{VII - Parametrização do Fluxo $L_{a}$ ?, e sua Relação com L ?,}

Sob condições de céu claro, as estimativas urbanas de L? podem ser diferentes das medições por causa da variabilidade dos aerossóis atmosféricos (OFFERLE et al., 2003). Ao comparar seis fórmulas de emissividade, para condições de céu claro, Prata (1996) encontrou rmse (root mean square error) variando de 10 a $22 \mathrm{Wm}^{-2}$ para uma grande variedade de locais.

Devido L? ser menos observado que K?, é apresentada uma estimativa de L? e analisada sua validação em relação aos fluxos observados no trajeto e à ocupação do solo. Utiliza-se um modelo atmosférico de uma única camada (OFFERLE et al., 2003), tal que:

$$
\mathrm{L}_{\mathrm{a}} \text { ? }=\mathrm{e}_{\mathrm{a}} \mathrm{sT}^{4} \text { ceu }
$$

onde $\mathrm{T}_{\text {ceu }}$ é a temperatura atmosférica volumétrica (em graus Kelvin) aproximada pela temperatura próxima à superfície $\left(T_{a}\right)$ e e é a emissividade atmosférica ampla $\left(\mathrm{e}_{\text {claro }}+\mathrm{e}_{\text {nuvem }}\right)$ estimada. Os esquemas de emissividade para o céu claro $\left(\mathrm{e}_{\text {claro }}\right.$ ) ao nível da superfície têm sido revistos com detalhes em várias localidades (PRATA, 1996; CRAWFORD e DUCHON (1999); NIEMELÄ et al., 2001) e a formulação de Prata (1996) tem sido a mais recomendada:

$$
\mathrm{e}_{\text {claro }}=1-(1+\mathrm{w}) \exp [-(1,2+3,0 \mathrm{w})]^{0,5}
$$

Esta expressão é preferida também por incluir testes para uma área urbana (NEWTON, 1999 in OFFERLE et al., 2003).

Em (13), o parâmetro w é representado pelos valores atmosféricos médios da pressão de vapor $\left(e_{a}\right)$ e de $T_{a}$ na altura da camada superficial de referência (nível da cobertura do 
veículo, a aproximadamente $1,75 \mathrm{~m}$ acima do piso do canyon):

$$
w=46,5 e_{a}\left(T_{a}\right)^{-1}
$$

A pressão de vapor corresponde a uma fração da pressão de vapor de saturação, definida pela umidade relativa (em \%) próxima à superfície $\left(U R_{a}\right)$ :

$$
\mathrm{e}_{\mathrm{a}}=10^{-2} \mathrm{e}_{\mathrm{sa}} \mathrm{UR}_{\mathrm{a}}
$$

onde, segundo Bolton (1980), a pressão de vapor de saturação (em hPa) pode ser descrita como função apenas da temperatura do ar em ${ }^{\circ} \mathrm{C}$ :

$$
e_{\text {sa }}=6,1078 \exp \left[7,5 T_{a} /\left(237,3+T_{a}\right)\right]
$$

Aplicando-se a parametrização descrita acima aos valores de temperatura do ar e umidade relativa observados no período do experimento (já apresentado no ítem anterior, durante a análise do conforto ambiental), obtém-se um fluxo de $L_{a}$ ? de aproximadamente $385 \mathrm{Wm}^{-2}$, ou seja, da mesma magnitude que os fluxos observados para os setores do percurso com maior obstrução do céu pela vegetação. No entanto, esta parametrização deveria resultar em valores inferiores a 360 $\mathrm{Wm}^{-2}$, pois é o que se esperaria a partir das observações, tendo em vista uma situação de céu claro para os setores com menor obstrução do céu.

São consideradas, na discussão adiante, modificações nos padrões de temperatura e umidade do ar que possam implicar em alterações de $L_{a}$ ? parametrizado. Oke (1978) apresenta a poluição atmosférica como um elemento que também pode contribuir para o aumento no fluxo de $\mathrm{L}_{a}$ ?. Mais tarde, o próprio Oke (1981) ressalta a importância da geometria urbana, em detrimento do fator poluição, como elemento preponderante para o aumento da radiação térmica observada na superfície. No caso do local estudado, por apresentarem os canyons uma relação $A / L$ baixa, talvez este fator poluição não devesse ser desconsiderado em setores com maior visibilidade do céu, ainda mais levada em conta a presença de um anticiclone pré frontal no período do experimento.

De fato, Ribeiro e Azevedo (2005) mostram através do mapeamento de concentrações do material particulado total em suspensão na RMSP, que a CUASO apresenta melhor qualidade do ar em relação ao entorno urbano, com concentrações abaixo dos padrões permitidos. Todavia, estas concentrações, como verificam Almeida et al. (2002), não podem ser consideradas desprezíveis, já que é observada para a localidade da CUASO um índice médio anual de aproximadamente $54 \mathrm{mgm}^{-3}$. Este índice corresponde a cerca de $3 / 4$ do índice médio no entorno imediato e a metade do índice observado nos setores mais poluídos da RMSP.

Deve-se deixar claro que a parametrização aqui aplicada corresponde aos métodos apresentados na literatura para uma situação de ar limpo, onde apenas o conteúdo de umidade é considerado como contribuinte para as variações nas taxas de $L_{a}$ ?. Mas um esforço ainda precisa ser feito para que futuras parametrizações venham considerar a presença dos poluentes atmosféricos, sobretudo em ambientes urbanos; mesmo que nas localidades estudadas as concentrações observadas ainda não tenham ultrapassado o limiar prejudicial à saúde.

Com a realização de alguns testes de sensibilidade em relação à formulação apresentada anteriormente verifica-se que elevações da temperatura do ar implicam também em elevações no fluxo $L_{a}$ ? calculado, o que contraria ainda mais as observações sob céu desobstruído. Todavia, considerando-se a temperatura do ar uniforme e reduzindo-se a umidade do ar, até sua total extinção ( $a r$ totalmente seco), obtém-se um fluxo $L_{a}$ ? de aproximadamente $324 \mathrm{Wm}^{-2}$, inferior aos valores mínimos observados (característicos dos setores com menor, ou muito pouca, obstrução do céu).

Considerando-se um ligeiro aumento da temperatura do ar, da ordem de $0,5^{\circ} \mathrm{C}$, e uma brusca redução da umidade relativa em cerca 
de $20 \%$ (situação extremamente seca, com umidades relativas entre 05 e $10 \%$ ), obtém-se valores de $L_{a}$ ? em torno de $340 \mathrm{Wm}^{-2}$, ou seja, com a mesma magnitude dos valores observados para a situação de céu aberto.

A estação meteorológica fica localizada na pequena depressão radiométrica do máximo indicado por $\mathrm{T}_{12}$ na Figura $6 \mathrm{~b}$, ou seja, entre áreas arborizadas. Portanto, considerando-se que as medidas de $L$ ? de intensidade mais baixa provém de setores asfaltados com pouca ou quase nenhuma vegetação, parece razoável assumir-se uma situação de ar ligeiramente mais aquecido e com reduzida presença de vapor d'água já que há uma maior impermeabilização do solo e esperam-se menores taxas de liberação de calor latente nestes setores. O que parece condizer de forma mais fidedigna à realidade sentida pelo pedestre neste ambiente.

\section{VIII - Conclusões}

O padrão de emissão térmica observada por Machado e Azevedo (2005), com um máximo bem definido sob uma área densamente arborizada, é verificado. Outros dois máximos, com magnitude semelhante (próxima aos $400 \mathrm{Wm}^{-2}$ ), são também identificados em outros setores do mesmo percurso com ocupação do solo semelhante.

A correção de Fairall et al. (1998) não deve implicar em alterações significativas sobre os dados coletados. A velocidade de ventilação estimada (cerca de $3 \mathrm{kmh}^{-1}$ ), para a manutenção de um equilíbrio térmico apropriado entre a cúpula que protege o sensor e o corpo do aparelho, mostra que a velocidade de deslocamento do veículo $\left(40 \mathrm{kmh}^{-1}\right)$ é suficiente para eliminar o efeito de aquecimento radiativo. Este efeito tem conseqüências maiores para plataformas fixas, onde o período de exposição direta aos raios solares ocorre em uma escala temporal superior (algumas horas) e pode haver ausência de ventilação natural.

A variabilidade da ocupação do solo, para o trajeto percorrido, é, em geral, caracterizada por diferenciação do tipo da vegetação (árvores menores com copas pequenas e árvores maiores com copas muito mais largas). Esta variabilidade, do tipo de vegetação presente, acarreta uma elevação do fluxo de L? observado, de aproximadamente $60 \mathrm{Wm}^{-2}$.

Quantidades adicionais de emissão térmica podem atingir a superfície e retardar seu resfriamento devido não apenas a edificações que obstruem o céu em um ambiente tipicamente urbano, mas, também, devido à emissão da face inferior de copas de árvores ou outros tipos de vegetação, que são característicos de ambientes não urbanizados.

O índice de conforto ambiental analisado (NIKOLOPOULOU et al., 2002) parece apresentar uma resposta mais coerente quando se adapta a sua formulação um termo que considere o fluxo $\mathrm{L}$ ? proveniente das diversas superfícies. O setor arborizado, que apresenta ligeira sensação de frio para o índice original, passa a indicar sensação de calor para o novo índice sugerido.

Em situações em que não há disponibilidade de observações da emissão térmica, a intensidade do fluxo $L$ ?, utilizada na nova formulação sugerida para um índice de conforto, pode ser substituída por um termo parametrizado. No qual, parâmetros derivados da temperatura e umidade do ar podem fornecer um resultado adequado, sobretudo observando-se as condições de ocupação do solo no local onde as variáveis meteorológicas são coletadas.

\section{IX - Agradecimentos}

Ao Prof. Dr. Amauri Pereira de Oliveira, do Dept $^{\circ}$ de Ciências Atmosféricas, do IAG - USP, pelo empréstimo do pirgeômetro e do datalogger. 


\title{
Nota
}

\begin{abstract}
1 Nadir, termo árabe que significa oposto. Corresponde ao oposto de zênite (samt, caminho), que por sua vez, equivale ao ponto culminante da abóboda celestial, posicionado justamente acima da cabeça de um observador na superfície (Bozcko, 1986).
\end{abstract}

\section{Bibliografia}

AB'SABER, A. N. Domínios morfoclimáticos e províncias fitogeográficas do Brasil. Orientação São Paulo, 3, 1997, 45 - 48.

ALMEIDA, L. T.; ASSUNÇÃO, J. V. and ESTON, S. M. Characteristics of suspended particulate matter in a University Campus area in São Paulo, Brazil. In: Proceedings Global Conference, São Paulo, 2002.

AZEVEDO, T. R. e J. R. TARIFA. Estudo comparativo do desempenho de minirregistradores digitais de temperatura e umidade do ar em abrigo meteorológico padrão e no miniabrigo meteorológico aspirado. GEOUSP - Espaço e Tempo, 11, 2002, 129 - 142.

BOCZKO, R. Conceitos de astronomia. Editora Edgard Blücher Itda., São Paulo, 1984, 429 p.

BOLTON, D., The computation of equivalent potential temperature. Monthly Weather Review, 108, 1980, 1046-1053.

CRAWFORD, T. M. e C. E. DUCHON. An improved parameterization for estimating atmospheric emissivity for use in calculating daytime downwelling longwave radiation. Journal of Applied Meteorology, 38, 1999, 474 - 480.

FAIRALL, C. W., PERSSON, P. O. G., BRADLEY, E. F., PAYNE, R. E. e S. P. ANDERSON. A new look at calibration and use of Eppley precision infrared radiometers. Part I: theory and application. Journal of Atmospheric and Oceanic Technology, 15, 1998, $1229-1242$.

FAIRBRIDGE, R. W. Encyclopedia of geomorphology: encyclopedia of earth sciences. New York: Reinhold. 1968.
GIVONI, B. Climate considerations in building and urban design. New York: John Wiley \& Sons, Inc., 1998, $464 \mathrm{p}$.

GRIMMOND, C. S. B. e T. R. OKE. Comparison of Heat Fluxes from Summertime Observations in the Suburbs of Four North American Cities. Journal of Applied Meteorology, 34, 1995, 873 889.

HU, Z., S. ISLAM e L. JIANG. Approaches for aggregating heterogeneous surface parameters and fluxes for mesoescale and climate models. Boundary-Layer Meteorology, 93, 1999, 313-336.

IZIOMON, M. G., H. MAYER e A. MATZARAKIS. Downward atmospheric longwave irradiance under clear and cloudy skies: measurement and parameterization. Journal of Atmospheric and Solar-Terrestrial Physics, 65, 2003, 1107 - 1116.

KRETZSCHMAR, J. G. Particulate matter levels and trends in Mexico city, São Paulo, Buenos Aires and Rio de Janeiro. Atmospheric Environment, 28, № 19, 1994, 3181 - 3191.

MACHADO, A. J. As circulações locais associadas à formação de nevoeiro na Grande São Paulo. Dissertação de mestrado, IAG - USP, 1993, $149 p$.

MACHADO, A. J. e SilLVA DIAS, M. A. F. The role of local circulations in summertime convective development and nocturnal fog in São Paulo, Brazil. Boundary-Layer Meteorology. 82, 1997, 135 - 157.

MACHADO, A. J. e T. R. AZEVEDO. Observações não-convencionais da radiação atmosférica na 
CUASO e imediações. Anais do II Seminário de Pesquisa em Geografia Física, Depto de Geografia da FFLCH / USP, São Paulo, 11 e 12 de dezembro de 2004, 657 - 662 (CDROM).

MACHADO, A. J. e T. R. AZEVEDO. Fluxo diurno de radiação de onda longa recebida em um trajeto urbano arborizado. In: XI Simpósio Brasileiro de Geografia Física Aplicada Geografia, Tecnociência, Sociedade e Natureza. São Paulo, 05 a 09 de setembro de 2005, 100 109.

NAKAMURA, Y. e T. R. OKE. Wind, temperature and stability conditions in na $E$ - W oriented urban canyon. Atmospheric Environment, 22, 1988, 2691 - 2700.

NIEMELÄ, S. P., P. RÄSÄNEN e H. SAVIJÄRVI. Comparison of surface radiative flux parameterizations. Part I: Longwave radiation. Atmospheric Research, 58, 2001, 01-18.

NIKOLOPOULOU, M.; S. LYKOUDIS e M. KIKIRA. Thermal comfort models for open urban spaces. In: Designing open spaces in the urban environment: a bioclimatic approach. RUROS (Rediscovering the Urban Realm and Open Spaces), 2002, 2 - 6.

NIR, D. Man, a geomorphological agent: an introduction to anthropic geomorphology. Jerusalem: Keter Publishing House. 1983.

NUNEZ, M. e T. R. OKE. The energy balance of an urban canyon. Journal of Applied Meteorology, 16, 1977, 11 - 19.

OFFERLE, B., C.S.B. GRIMMOND and T.R. OKE. Parameterization of net all-wave radiation for urban areas, Journal of Applied Meteorology, 42, 2003, 1157-1173.

OKE, T. R.. Boundary Layer Climates. Methuen \& Co Ltd, London, 1978, 372 p.

OKE, T. R.. Canyon geometry and the nocturnal urban heat island: comparison of scale model and field observations. Journal of Climatology, $1,1981,237$ - 254.

OKE, T. R.. The micrometeorology of the urban forest. Philosophical Transactions of the Royal
Society of London, Series B, 324, 1989, 335-351.

OLIVEIRA, A. P., A. J. MACHADO, J. F. ESCOBEDO e J. SOARES. Diurnal evolution of solar radiation at the surface in the city of São Paulo: seasonal variation and modelling. Theoretical and Applied Climatology, 71, 2002 (a), 231-249.

OLIVEIRA, A. P., J. SOARES, J. F. ESCOBEDO, A. J . MACHADO, G. CODATO e E. GALVANI. Diurnal evolution of surface radiation budget components in the cities of São Paulo and Botucatu. Anais do IX Congresso Brasileiro de Engenharia e Ciências Térmicas, 15 a 18 de outubro de 2002 (b), Caxambu, MG (CDROM).

PRATA, A. J. A new long-wave formula for estimating downward clear-sky radiations at the surface.Quarterly Journal of the Royal Meteorological Society, 122, 1996, 1127 - 1151.

RIBEIRO, H. e AZEVEDO, T. R. O patrimônio em áreas verdes da USP e a atmosfera urbana. In: Meio ambiente, patrimônio cultural da USP. CPC/ USP, EDUSP, São Paulo, 2005, 19 - 40.

ROGERS, R. e P. GUMUCHDJIAN. Cidades para um pequeno planeta. Barcelona: Editorial Gustavo Gili, SA, edição portuguesa, 2001, $180 p$.

ROSS, S. L. e T. R. OKE. Tests of three urban energy balance models. Boundary - Layer Meteorology, 44, 1988, 73 - 96.

ROTH, M., T. R. OKE e W. J. EMERY. Satellite derived urban heat islands from three coastal cities and the utility of such data in urban climatology. International Journal of Remote Sensing, 10, 1989, 1699 - 1720.

SAKAMOTO, L. L. S. Os Microclimas e a "Configuração do Céu" na Área Central. Os Climas na Cidade de São Paulo, Teoria e Prática. GEOUSP 4, 2001, 165 - 187.

SPRONKEN-SMITH, R.A. e T.R. OKE. Scale modelling of nocturnal cooling in urban parks. Boundary-Layer Meteorology, 93, 1999, 287312.

TARIFA, J. R. e G. ARMANI. Os Climas Urbanos. Os Climas na Cidade de São Paulo, Teoria e 
Prática. GEOUSP 4, 2001, 47 - 70.

THORSSON, S. e I. ELIASSON. An intra-urban thermal breeze in Göteborg, Sweden. Theoretical and Applied Climatology, 75, 2003, 93 - 104.

VOOGT, J. A. e T. R. OKE. Validation of an urban canyon model for nocturnal long-wave radiative fluxes. Boundary - Layer Meteorology, 54, 1991, $347-361$.

VOOGT, J. A. e T. R. OKE. Complete Urban Surface Temperatures. Journal of Applied Meteorology, 36, 1997, 1117 - 1132.

VOOGT, J. A. e T. R. OKE. Effects of urban surface geometry on remotely - sensed surface temperature. International Journal of Remote Sensing, 19, 1998 (a), 895 - 920.

VOOGT, J. A. e T. R. OKE. Radiometric temperatures of urban canyon walls obtained from vehicle traverses. Theoretical and Applied Climatology, 60, 1998 (b), 199 - 217.

VOOGT, J. A. e T. R. OKE. Thermal remote sensing of urban climates. Remote Sensing of Environment, 86, 2003, 370 - 384.

YANAGIHARA, J. I. Programa de computador avalia limites de controle térmico do corpo humano. In: Diário Oficial do Poder Executivo Seção I, São Paulo, 115 (211), 9 de novembro de 2005, p. III.

Trabalho enviado em fevereiro de 2006

Trabalho aceito em março de 2006 
